\title{
Inventing the Electronic University
}

\section{David W. Lewis}

Higher education is confronting a fundamental change. The transition from print on paper to digital and electronic technologies is transforming instruction, scholarly communication, and the storage and preservation of knowledge. What is required is not the automation of old systems, but the restructuring of institutions. The drive for autonomy, needed for effective scholarship, and the push for standardization, needed to assure easy and open access to information, will create conflicts difficult to resolve. Universities must find new ways of funding and financing information services and new staffing patterns if they are to continue as effective learning and research centers.

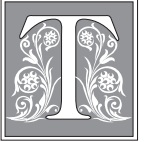

wice in recent years librarians, joined by faculty and university administrators, have gathered at corporate conference centers to consider developments in communications and computing technology and their effects on the scholarly enterprise. The first meeting was held at Conoco's Purple Sage Ranch in Bandera, Texas, in November 1985 under the auspices of the Research Libraries Group. The second followed eight months later, sponsored by OCLC at the Johnson Foundation's Wingspread Conference Center in Racine, Wisconsin. ${ }^{1}$ These gatherings demonstrated a commitment to, in Patricia Battin's words, "create an institutional capacity to reinvent the university in the electronic age." ${ }^{2}$ For 500 years knowledge has been communicated and stored largely through the use of printed documents. This technology is rapidly being supplemented and replaced by one that is digital and electronic. The power of the new media and the failings of the old system are driving scholarly institutions toward change.

For librarians, the papers presented at these conferences, and other recent works, are important because they mark a change of perspective. The change can be illustrated by comparing Battin's statement above with one she made only four years earlier. In 1980 she wrote, "We must reinvent the research library in the network environment." 3 Then the goal was to reinvent the library; today it is to reinvent the university. A dramatic shift, the issue is no longer library automation: it is remaking the structure of scholarly communication. Many in the academy may be surprised that librarians have these concerns, but as Hugh Kenner, citing the examples of the incandescent light and the copying machine, states, "One lesson the past has to teach is that every new technology, when it applies for admission to a citadel of the intellect, has invariably received its first welcome from the librarian."

This is a time of transition and fundamental changes in institutions. The research university, for 100 years the locus of scholarly communication, has become a large,

David W. Lewis is Lehman Librarian at Columbia University, New York, New York 10027. 
inertial social and institutional structure. It is also a playing field, where intellectual contests not only advance knowledge, but reap rewards of prestige and funds for the players. The current debate over the course and extent of the change is complicated because the participants, almost without exception, have a stake in the existing structure and play the academic game. This paper will attempt to sort through the rhetoric and to bring the issues into focus. For if this transition is not carefully considered it will be, as Wilfred Lancaster warned a decade ago, "one of disruption and chaos rather than one of ordered evolutionary progress." ${ }^{5}$

\section{Learning and Teaching}

The use of computers for teaching holds great promise but also threatens to disrupt traditional roles and practices. Richard Cyert, the president of Carnegie-Mellon University, sees a revolution resulting from the instructional use of electronic media in higher education. He cites three ways in which the computer will have an impact. First, it will increase students' comprehension by building complex simulations and "real world" problems. Second, "intelligent tutors" will guide students, at their own pace, through the body of knowledge to be mastered. Finally, the computer, by acting as a gateway to large bodies of knowledge, will expand students' ability to learn on their own. ${ }^{6}$ But what Cyert sees as revolutionary, Harvard's president Derek Bok, after reviewing similar developments, sees as an occasion for cautious enthusiasm." ${ }^{7}$ Such is the range of views.

In a closer look at instructional technology, Gregory Jackson defines four classes of software: (1) "computer assisted instruction" (CAI) software, which "tutors," usually through individualized drill and practice; (2) "tool" software, such as word processors, which manage the procedural details that often interfere with learning; (3) "problem" software, which serves the same purpose as any problem set, but can be more complex; and (4) "simulation" software, which allows students to experiment easily with reallife situations and observe the results. ${ }^{8} \mathrm{CAI}$ is usually an individual activity, and the other three are often used by groups of students. Most of the applications now in use are CAI. Jackson suggests that its focus on individual activity may be one reason for CAI's lack of impact, an interesting insight in light of current thinking on collaborative learning which argues the most effective way to think about learning is to focus on its social nature. It takes place among people, not between a person and things. As Kenneth Bruffee argues, "Students learn better through noncompetitive collaborative group work than in classrooms that are highly individualized and competitive." 9 The combination of a collaborative style of teaching with tool, problem, and simulation software may present an opportunity for significant improvements in instruction.

Maurice Glicksman, noting the failure of computer technology to significantly affect instruction, reminds us that even though most faculty have no pedagogical training, they generally consider themselves good teachers and see little need to change their methods of instruction. ${ }^{10}$ The resistance that Glicksman cites is compounded because teaching in general and the development of instructional software in particular are not highly valued academic activities. ${ }^{11}$ In addition, the development of effective teaching software requires skills not often possessed by teaching faculty. Knowledge of the subject, an understanding of cognitive theory, and an ability to combine the two into a software package are all required. Richard Van Horn expresses a very different view. For him faculty are not the key; rather, making electronic tools available for students' use is what matters. Then, as he says, "All the faculty member must do is assign problems relevant to the discipline, and students will decide how to solve these problems.... Students can use computing whether a faculty member loves computing, knows anything about computing, or even cares." ${ }^{12}$ For many years the library has been 
the primary teaching tool outside of the classroom, and except for faculty, librarians have been the only university staff to assist large numbers of students in the academic process. The use of other technologies will require new skills and will involve other staff in academic activities outside the classroom.

The revolution in instructional technology will also change libraries. First, librarians can put the technology to use themselves. Much of what needs to be taught about library use is tutorial and appropriate for computer packages. Second, and more importantly, there will be competition for resources, both dollars and space. The university will need to decide where to locate the new computer tools, both physically and administratively. Libraries are an obvious choice, but many librarians will be uncomfortable supporting tools rather than resources, especially if no new money accompanies the request for service. There will be debates like those over nonprint materials, and the result will be similar. Community colleges and medical schools, where nonbook materials are already common, will slide easily into the new role, as may four-year residential colleges where the library is already one of the centers of campus life. University libraries, especially those associated with prestigious universities, will have a more difficult time accepting this nontraditional role.

An important impact will be rising user expectations. Students may expect the library to be as powerful and easy to use as electronic teaching tools. Unfortunately, libraries are rarely easy to use. If analysis with new computer tools becomes easier and more productive than library research, students can be expected to use the new tools rather than the library. If libraries do not improve their services so that they remain an essential teaching tool, they risk becoming irrelevant to the teaching process. If this is allowed to happen, it is easy to predict a decline in library funding.

There will also be opportunities. If, as Van Horn suggests, improvements in learning will come not in the classroom, but outside of it, librarians and other support staff will have a key role to play. Librarians combine a knowledge of the academic process with an attitude of service unique in the university. But, university libraries and librarians have been strained and stretched by the breakdown of the paper system of scholarly communication. Much of the stress has been passed on to library users in the form of lines, cataloging backlogs, and inadequate service staffs. As the process of scholarly communication becomes more completely electronic, efficiencies will come into play and library service both inside and outside the library should improve. To take a mundane example, when books and articles are online, there is little reason to require students to wait in lines at reserve desks, or even come to the library, to read them. Librarians will be able to create and provide information resources that reach beyond their walls. Dial-up access to the catalog will be only the beginning. Grolier Electronic Publishing already offers site licenses for the Academic American Encyclopedia, Facts On File, and a number of other standard reference sources, and Carnegie-Mellon University provides access to this material through their campus network. ${ }^{13}$ Similar developments have been reported at the Georgia Institute of Technology. ${ }^{14}$

To make the new modes of instruction successful, librarians will have to abandon comfortable roles, and the library will need to become the institutional provider of scholarly tools in all forms. The most important tool will be, as it has always been, the ability to communicate with the scholarly record. Books will continue to play a large part but so will databases of all kinds. Also required will be tools to manipulate the scholarly record: word processors, statistical and graphics packages, concordance programs, and simulations. All will have their place. In its electronic form the scholarly process will become seamless; students and faculty will use the same machines for data collection, analysis, and communication. The library will need to encompass all of these activities. It must become, in John Sack's phrase, "the public space for scholarship on campus. ${ }^{15}$ 


\section{Communication Between Scholars}

Forty years ago Vannevar Bush, noting the press of scholarly work, proposed a device, what he called the "memex," that was probably the first expression of the scholar's workstation. The device was to serve as a researcher's personal information system. ${ }^{16}$ What is usually remembered about the memex is the use of microfilm as the storage medium. One has an image of a 500-pound desk with lots of screens, motors, and whirling reels. It is easy to chuckle at Bush's mistaken choice of medium. But more importantly, he was incorrect in a fundamental way - the memex was unconnected. What is important about today's personal computers is not that they have the capacity to store books, but that they can communicate. As Francis Crick has said, "communication is the essence of science," and indeed all scholarship. ${ }^{17}$ Electronic communication is not simply a link to colleagues, but a link to resources. It can replace storage, or as a librarian would put it, access can replace ownership.

When we consider the effects of the electronic media we must begin with the essential fact-the formal print system is no longer adequate. More than 300 years ago the scholarly journal was created because scientists could no longer keep up with each other's work through word of mouth and correspondence. The weight of the system, based on the printed scholarly journal, has become more than existing structures can bear. The evidence is all around us. Publishing delays are such that no self-respecting scholar depends on journal publication as a primary means of staying current. Preprints and working papers have become a way of life, and formal journal publication is more for posterity and tenure committees than communicating with colleagues. Journals proliferate and become more specialized, and libraries can no longer afford to acquire this scholarly output. Scholars are overrun with a deluge of publications, many of which add little to the corpus of knowledge.

Kenner suggests that one of the problems with the paper system is that we have been asking it to do things for which it is not well suited. ${ }^{18}$ He points out that the paper publications are mass produced, and as such must be made in quantity. The mechanics slow the process, and the economics require that many copies will be uselessly stored on library shelves. Kenner points out that in many situations alternative forms of communication would be preferable. As he says, "much scientific communication is essentially news, news of what's going on in whose lab, news only interesting when it is hot."19 He cites the distribution of dissertations on demand by University Microfilms as one appropriate alternative. The emerging electronic technology promises to provide others.

The electronic journal is an early example. The first attempts were not entirely successful, ${ }^{20}$ but the more recent BLEND experiment has demonstrated the feasibility of such a system. Like earlier attempts, BLEND showed that mechanics, such as ease of access to terminals, cause much of the difficulty. ${ }^{21}$ The personal computer, with its word-processing and communications capabilities is, as Donald Case puts it, "the 'missing link' between yesterday's and today's methods of publication.". 22 A recent study in the social sciences and humanities indicates that most scholars now have access to computers and close to half have a personal computer for their exclusive use..$^{23}$ The more important point that Case makes is that scholarly communication is a bottom-up enterprise. When scholars find that it is easier to keep in touch by electronic mail, they will use it or any other method that works. Electronic means of scholarly communication will not have a quick or radical effect. As Priscilla Oakeshott predicts, based on the BLEND experience, the more likely result will be, "the gradual integration of electronic publishing with on-demand printing and retrieval systems over the next twenty years or so." ${ }^{24}$ An array of communication options will be available, from electronic mail messages arranging lunches to electronically referred journals. In this world the distinctions between formal and informal communication will blur. 
Bryan Pfaffenberger argues that electronic communication has the potential to reduce the tendencies toward elitism and internal stratification present in much of scholarly communication. As he states, "Because computer-based communications media tend to foster group attachment, a focus on intellectual issues, equity among participants, and informality, they seem ideally suited to research network communication." 25 Pfaffenberger suggests that small-scale systems based on personal computers or public access systems such as the Source will have greater impact than large, expensive systems such as ARPANET, the Department of Defense research network. Michael Spitzer looks at communications in computer conferencing systems and discusses the in between nature of the medium. It lacks both the permanence of written prose and the personal presence of face-to-face conversations. Like Pfaffenberger, Spitzer notes a leveling and democratizing effect of electronic communication. It rewards, he claims, clear thinking and persuasive writing, without necessarily giving clues as to the author's status or position. ${ }^{26}$

Electronic communication can make research data that are not now easily accessible available to many users. Up to now, the data collected for one research project has rarely been usable by another researcher, but his is changing. To quote Kenner:

But as more and more material gets onto tape and disc, for whatever purpose, more and more workers are going to be thinking of other things to do with it: a departure from the rule that used to govern all research, that raw material, raw data, gathered by no matter what effort, never seemed to get used a second time by anybody... But we are now able to think of such data as a community resource. Moving it around the continent by modem or even mail will soon be, I hope, routine. ${ }^{27}$

The Inter-University Consortium for Political and Social Research already fills this role to some extent for numeric social science data sets, and some journals have taken to distributing programs and data on floppy disks in conjunction with printed articles. At least one scholarly journal, World Cultures, is published only on floppy disks. Problems with documentation and data integrity, exist but this established trend will continue.

The formal paper-publishing system serves not only as a means of communicating and storing ideas, but as Alan Singleton states, "The journal plays a crucial role in the social system of science, conferring public recognition and thus reward on authors of published papers." ${ }^{28}$ Singleton identifies the criteria an electronic system must have if it is to replace the printed journal's social role. First, all authors must have access to the system; it can not operate on closed networks. This problem already exists. Douglas E. Van Houweling states that ARPANET has become such an important means of communication in a number of fields that, "persons without access ... are effectively cut off from effective collaboration." ${ }^{29}$ Second, all interested readers must have access to the system. The availability of appropriate equipment has been largely overcome, but restrictions on transnational data flow complicate the creation of an international electronic journal. Beyond these two criteria the system must have accepted prestige. Articles, whether read or not, can be counted by review committees, and the pecking order of academic journals is well understood. Similar recognition will need to be granted to electronic forms of scholarly communication.

Beginnings can be seen as the editors of Medical Care stated when they distributed a floppy disk containing a computer program with their July 1987 issue, "The academic reward system traditionally values the printed scholarly publication. In our opinion, accessible computer programs should be given equal, and on occasion more, weight in judging an academic research career." ${ }^{30}$ Disciplines where the results of research 
can be separated from the reporting of results will find the transition easier than disciplines where a large part of the scholarly task is the expression of understanding. A biochemist receives a Nobel Prize for work done in the lab, but a historian will receive a Bancroft, not for work in an archive, but only for a book.

In the paper system, printed materials are an institutional resource. A university's library is among its most valuable, if not always most appreciated, possessions. Scholars cluster around university libraries because they are necessary tools. An electronic system makes possible the distribution of resources, and scholars will not need to be associated with large universities to have access to the corpus of knowledge in many fields. Electronic mail and conferencing systems can connect colleagues even if they are not on the same campus. Many scholars already feel isolated; the recent ACLS report on scholarly communication indicates that 25 percent had no one in their department who shared their research interests. ${ }^{31}$ Electronic means of communication will help overcome the isolation, but the social impact will not stop there. In the past, the large library collection available only at a large established research university was a requirement for world-class scholarship. Tomorrow, a wide range of scholarly resources will be available at smaller institutions. Great libraries alone will no longer draw or keep the best faculty.

\section{Preservation and Access}

The conservation of knowledge by collecting and preserving the artifacts containing recorded information has been one of the library's historic missions. The library's other traditional mission has been to make the accumulated stock of knowledge available for use. In the print system, information is distributed as a physically tangible object-a book or journal. The information is locked in an unchangeable state when it is printed and becomes a fixed piece of the written record. Both the preservation and distribution of the information are tied to the physical artifact. Libraries, especially academic research libraries, have long been caught in the dilemma of wanting to encourage use, which threatens the physical object, and to preserve the object, which limits use. The electronic medium has the potential to resolve this conflict. The physical form of electronic information, at least in theory, makes distribution to many people across great distances and secure storage compatible.

If this sounds too good to be true, it may be. As Gordon Neavill, in a thoughtful study of the problems of the electronic media for libraries, states

The malleability of information that is one of the major advantages of computerbased electronic systems has its corollary the potential transience of information. Nothing inherent in the technology of computer-based electronic systems ensures that information in the system will survive.... When information is freed from the confines of a physical container it is rendered vulnerable. It can be altered or revised without any indication that a change has been made. It can be purged from the system altogether. Information without a physical container cannot survive on its own. ${ }^{32}$

It is interesting to look at Neavill's concerns in the context of Timothy Weiskel's structuring of the problem. Weiskel begins by defining information as the nonrandom arrangement of energy or matter, and, because entropy drives both energy and matter toward a random state, no such arrangement can be permanent. Because this is so, Weiskel argues, to preserve information it must be renewed by switching it from one medium to another. Weiskel calls this activity channel switching, and for him it has always been a library function. With the advent of new and powerful channels 
he predicts that moving information between different media, both to distribute it and to preserve it, will become increasingly important. ${ }^{33}$ The switching technology exists. Optical scanners are being developed that can recognize many typefaces and alphabets and can digitize text at speeds of 50 to 100 pages an hour. Once digitized the information can be stored on magnetic, optical, and even paper media. The magnetic media are malleable and flexible; they allow for the easy manipulation of information. Some optical media, such as CD-ROMs, are mass-produced and can be used flexibly, but are not malleable. Write once read many (WORM) optical technology need not be mass-produced. Paper digital systems are as of yet largely unapplied, but they appear to have all the advantages of other paper media. ${ }^{34}$ The important point is that digital information makes the channel-switching process significantly faster and easier than it has ever been before. There exist any number of containers for digital information; taken together they should be able to meet all the requirements for preservation, distribution, and manipulation of recorded knowledge.

The ease with which digital information can be copied from one medium to another raises significant concerns for the ownership of intellectual property. Current concepts of intellectual ownership will probably not hold up in the digital environment, and this will lead to an instability in the information marketplace. Copyright has served as the protection for a publisher or author's return on investment. If electronic media render this protection ineffective, other mechanisms will need to be developed. Some of these will certainly be in conflict with the desire for unencumbered distribution of information. Universities and their libraries may be required to act as agents of control if they are to acquire some kinds of commercially produced information. Another view, which is either realistic or shortsighted, is expressed by D.I. Raitt,"Copyright? Forget it!... So long as the library has it or can get it-who cares who owns it? Anyway possession is nine tenths of the law!" 35

The ease with which electronic media can be used will have another effect. Many items that have not been published in the traditional sense will be broadly distributed. Publishers, with their editorial screening and quality control, have been gatekeepers of the public record. The loss of the publication hurdle, which occurs when everyone becomes a desktop publisher, will lead to an enormous increase in low-quality materials, and the already challenging intellectual task of selecting items for inclusion in library collections will become even more difficult.

The routine use of electronic communication by scholars and students can be expected to change not only the way they work, but the roles played by the library in the process. It may be useful to look at online searching for some of the trends. As the first electronic component of the scholarly communication system, bibliographic databases have been widely used for over a decade. These databases are usually supplements, rather than substitutes, for the printed versions and were, until recently, accessed primarily by librarians. In the last year or two this picture has changed. New systems, pricing schemes, and marketing aimed at the "end-user," have changed the librarians' role from the intermediary to the facilitator who provides access to terminals, instruction, and guidance in choosing the best system for the task at hand. Importantly, the library continues to make information available to all members of the community. This has not been without stress. Funding expensive systems and the need to control costs on pay-as-you-go systems make free unrestricted use difficult.

The university, through its library or some other mechanism, will need to provide access to networks, bulletin boards, and electronic journals just as it has provided access to the printed record. The systems acquired and the barriers to access, such as fees or limited access to terminals, imposed will in large part define the working environment of the university. As electronic scholarly resources become widely available, institu- 
tional status will not be enhanced simply by owning materials. What will matter in the competition for students and faculty will be the ease of access to information and the extent to which the institution will pay the bills.

\section{Standardization or Autonomy?}

The fundamental issue in the application of electronic technology to scholarship will be the balance between central control and standardization, on one hand, and the need of individual scholars to apply idiosyncratic applications to special situations on the other. Much of the current opinion leans toward decentralization and away from central control. Van Houweling makes this case strongly and clearly:

The strength of higher education is derived from its decentralization and diversity. Since the new economics of information technology reinforce these institutional characteristics, diversity and decentralization will be fundamental to achieving our information technology goals. As a result, central activities need to be carefully targeted and designed so as to make the maximum amount of resources available to the various decentralized units in our colleges and universities. Therefore, while almost any information technology activity can be accomplished, in principle, through a central organization, the best organizational strategy for the future is based on quite the opposite premise.

Information technology activities in higher education should be pursued at the lowest level of the organization consistent with their efficient and quality performance. $^{36}$

However, this view is not universally held. Battin argues the other side:

The paradox of our situation is that the achievement of our goal, because of the character and cost of computer and communications technologies, will require a substantial level of initial cooperation and centralization that runs counter to the strongly autonomous nature of scholarly inquiry. The very diversity of scholarly inquiry and information needs requires in the electronic age an unprecedented degree of centralized, coordinated linkages and compatibilities to serve that diversity and permit the autonomy necessary for productive and creative scholarship. ${ }^{37}$

An important aspect of this debate involves administrative structures. Many observers have suggested the convergence of the library and the computer center. ${ }^{38}$ The electronic technology has created a situation in which these two organizations share similar resources and service responsibilities. Many campuses have already begun to integrate academic computing and library services, and, at least among librarians, the good sense of this approach is no longer an issue for debate. The more important concern is the conflict between the central organization and the many, often semiautonomous, departments, institutes, and centers that make up the university. The question will be who buys what machines with which money. The debate will be over turf, but as Weiskel reminds us the relationship between scholars and libraries is symbiotic. ${ }^{39}$ Faculty need to be involved in planning for the university's use of electronic technology, but this is not always the case, as the example of Brown University's scholar's workstation project shows. ${ }^{40}$

For Sack it is less the autonomy required by the scholarly process than the nature of the technology that will make centralized control impossible. For him the real revolu- 
tion will be in the way individuals adapt to the new tools. He believes the malleability of electronic information and the openness of the systems containing it will "combine to encourage the spread of information and ideas beyond the capacity or control - for better or for worse- of information specialists." ${ }^{41}$ Sack suggests that the openness of information systems will allow institutions to become more flexible. An institution should become, as he says, "more able to shape itself to the scholar, becoming less a specific place than a service and a near-transparent medium." ${ }^{42}$ To do this will require a change of orientation. The traditional "Ptolemaic," or institution-centric view needs to give way to a "Copemican," or scholarcentric view. The fundamental truth of Sack's analysis is that the technology will allow a department or an individual to supply services for themselves if central services are not appropriate to their needs. The result many not be in the best long-term interest of the university.

It is difficult to argue that institutional changes are not in order. Diseconomies of scale are clear in most research libraries and many university computer centers. Concurrently, the ease with which information can be communicated has outstriped the individual scholar's ability to manage it. Institutional support must be used to build networks and to assure open communication. The extent and complexity of the technology require that the integrating network function be institutionalized. It will also be necessary to identify electronic resources within the university, to assure access to them, and to preserve them. In this effort, incentives rather than regulation will be effective. Individual scholars and departments need to be convinced that centrally controlled systems can provide better service than they could provide for themselves. If they are not convinced, they will go their own way. What Richard W. McCoy says about library networks is also true about electronic structures within the university, "It is of critical importance that research institutions spend the time it will take to understand and internalize the apparently subtle difference between decentralized (fragmented) vs. distributed processing." ${ }^{43}$

\section{Issues of Staffing}

The ability of individuals to tap into the electronic systems and to access resources without a large up front investment may lead toward deinstitutionalized information services. Scholars have always created their own information systems by building personal collections of books and journals, by traveling to conferences, and by maintaining a network of colleagues. It is therefore not unreasonable to expect them to add electronic sources to their repertoire. The more interesting change may come to librarians, who may now be able to function independently. R.R. Featherlingham suggests that reference librarians and information specialists, "may tend increasingly to freelance their services, to bring their remuneration more under their own control." ${ }^{44}$ This trend is already apparent in business, but academics, except those with large grants, do not have the cash required to support freelancers on a large scale. Nonetheless, it is easy to imagine academic reference librarians moonlighting. This possibility raises ethical and policy issues that few libraries have faced.

Evelyn Daniel suggests that librarians will need to work more closely with research teams because of the complexity of information systems and the interdisciplinary nature of many projects. ${ }^{45}$ When access replaces ownership as a significant means of providing scholars and students information, high-quality reference and consultation services will become part of expected institutional support. This will likely lead to an organizational structure based on client-centered work groups as suggested by Charles Martell. ${ }^{46}$ The client centered approach will require staff with strong subject backgrounds and an understanding of the scholarly process as well as library and computer skills. In fact, the former may be more important than the latter. 
Diane Cimbala considers the Scholarly Information Center model as presented by Battin and points out a number of potential problems of combining library and computer center staffs. ${ }^{47}$ Academic librarians are generally required to have at least a M.L.S. and often a second subject master's degree; the profession is largely female, and salaries are generally low. Computer center personnel in equivalent positions often have only a B.A.; they are more likely to be male, and they enjoy higher salaries and opportunities for lucrative employment outside the university. Librarians are often faculty, or have "academic" rank; computer center personnel are generally considered staff. Combining these two groups into one organization has the potential to cause much tension. Librarians have for many years distinguished between professional and nonprofessional staff with the M.L.S. being required for entry into the professional class. The organizational structures that will be required for effective service in the electronic environment may require groupings of staff with many backgrounds, and the class structure may be forced to give way.

\section{Issues of Funding and Finance}

There are two mechanisms that can be used to fund information resources or any other general service in the university. Contributions can be taken from all members of the university community in the form of "tax," or fees can be imposed for use. The traditional mechanism for funding libraries has been a tax, usually as a percentage of general funds allotted to the library from tuition, gifts, and the administrative overhead on grants. Occasionally, as in the case of online searching, libraries charge for services on a fee-per-use basis. In these cases, the demand is usually price sensitive, and use is low. The computer center, on the other hand, has generally supported itself by the imposition of fees for use, usually through the sale of CPUs. In the past these systems have worked for both libraries and computer center. Because most of their costs have been fixed, libraries have been able to manage on a set budget allocation. For computer centers, until the recent influx of naive computer users who require large amounts of support, most services could be tied to CPU use, and costs could be covered by billing back to departments and outside users on this basis.

Ironically, as the library becomes more like the computer center and the computer center becomes more like the library, the traditional funding mechanisms have begun to fail. When libraries provide information by assessing online systems their costs are often variable. In these cases, fees are usually imposed to recover costs; this has tended to limit use of these systems. As Nancy Kranich points out, many libraries discourage use by charging fees while at the same time aggressively promoting their services. Fees therefore undercut attempts by the library to establish itself as the information center on campus. ${ }^{48}$ However, if fees are not charged, there is real danger of losing control of costs. Fortunately many online systems have moved to flat fees or subscriptions, and $\mathrm{CO}-\mathrm{ROMs}$ are fixed cost systems. Even so, as information becomes more and more a service and less and less a set of purchased items, price structures will become more complex. Libraries also must supply, at least in the short term, services in parallel forms. During the transition, both printed and electronic copies of the same sources will need to be acquired. This duplication will put severe pressures on library budgets.

Computer centers are also in a difficult situation. With the introduction of small powerful computers, many individuals and departments are purchasing their own machines. As a result they no longer use central time-shared equipment; they no longer buy CPUs, and computer center income declines. At the same time, the individuals and departments need and expect the computer center to supply advice and consulting services; of course, they are expected to be supplied at no charge. Communication networks have increased in importance, and computer centers are usually asked to 
supply the technical and consulting support to install and maintain them. Unfortunately, rarely do substantial budget increases accompany the new responsibilities, nor are the full costs of networks billable.

Most computer centers have seen the services that have traditionally generated income decline and the demand for free services increase. Libraries are expected to supply variable cost services without charging fees, and computer centers are expected to supply a fixed-cost service with no tax base. They are both confronting severe budget problems as a result. The combination of the two organizations will not provide any financial relief to the university, but it may focus attention on the need. This is certainly to be preferred to the two competing in a zero-sum game.

Battin offers a structure that may lead towards a solution: "The vastly expanded potential for expensive services makes it necessary to analyze our information functions, regardless of format, and establish new policies for centrally subsidized services with a series of optional, incremental fee-based services available on request." ${ }^{49}$ The approach is supported by Michael Cooper's analysis of the nature of information. He shows that information is best understood as a merit good. A merit good is, as he explains, "a private good that society thinks is important enough to be supplied publicly. It is supplied by interfering with consumer preferences, because, left alone, the consumer would purchase less than society thinks worthwhile." ${ }^{50}$ Cooper goes on to conclude that in some cases and for some users information services should be supplied free of charge, as are Battin's subsidized services. In other cases and for other users direct charges should be applied. This is simple notion, but it belies the difficult political decisions that will be required to implement it. The university with its diverse needs will have great difficulty making these decisions, and disgruntled departments or individuals can easily set up their own systems in response to policies or prices that do not suit them.

However the decisions are made, two things are clear. First, the university will need to allocate more for information services. The new information technology will make students and faculty more productive, and, at some point, there will be a need to shift funding from faculty to infrastructure. Some of this has already happened; universities today are spending more on their libraries and computer centers combined than they spent on their libraries alone forty years ago. This trend will continue, but it will be hard fought each step of the way. Second, libraries must find ways to limit the need to provide services through both print and electronic means. In most cases this will require giving up print.

\section{Conclusion}

The creation of the electronic university will require radical thinking and action. As librarians, we must not be afraid to follow through on our ideas even when this requires reconsideration of orthodoxies and established practice. How we respond will in large measure determine whether our campuses succeed in making a smooth transition to the electronic world. Traditional approaches will be ineffective, especially if coupled with shortsighted notions of turf. Among the issues will be.:

- Structure. The structure of the information function in the university will combine the current functions of the library, the computer center, and the telecommunications office. Such a combination will quickly move beyond a common reporting relationship to a mixing and melding of staff and responsibilities.

- Educational Technology. There will be a need for a public scholarly space on campus. Here students will find the traditional reference services of the library, but beyond these will be everything from facilities for viewing Soviet television or listening to Mozart, to computing on all types of machines from micros to 
supercomputers. The challenge will be to integrate these sources and services to create an open and inviting environment for both individual exploration and group learning.

- Communications. Effective communications networks require standard protocols and compatible software. Without these, intellectual collaboration may become easier off campus than on, and it will be difficult to share institutional information resources. Together these restraints will render the university ineffective. The key to building and maintaining a campus communications infrastructure will be central control over the links to the outside. If control over these links is lost there will be little incentive for departments to cooperate or accept institutional standards. Battles to maintain control over links to supercomputers and networks such as Bitnet, and even OCLC or RUN can be expected.

- Electronic Archives. More and more scholarly resources will be created in digital form. Many of these will be raw data, and they will not be published by commercial firms. These data nonetheless have potential research value and will need to be preserved in a fashion that will allow their later use. Individual scholars will not be up to the task, and an institutional commitment will be required.

- Staffing. This issue will be particularly difficult for librarians who have fought long and hard to gain their present status in the university. The traditional skills provided by the M.L.S. and possessed by many practicing librarians will no longer be adequate for many positions. Subject experts and computer programers without library backgrounds or credentials will be hired. What it means to be a librarian will change, as may the name.

- Intellectual Property. Copyright in its present form will cease to be effective when information is digital and subject to easy transmission and manipulation.

Other mechanisms will be needed to assure that the creators of information resources receive an equitable return on their investment. Universities will need to resist inappropriate assertions of the right of "fair use." License agreements and other contracts will become common and will need to be carefully negotiated and honored.

- Funding. Ways will need to be found to both control costs and provide equitable access to information. This will require at least a two-tiered system. Some services will be provided free to all members of the university community and will be paid for from general university funds. Other services will be available only on a fee-per-use basis. Subsidies may be required when equity needs to be assured.

- Cooperative Programs. Universities will have to work together to create a series of regional and national resources centers to assure that scholarly resources are acquired and preserved. Printed materials need to be given first priority because of the great needs for preservation and because they will be the first thing given up by individual institutions. In addition, many electronic resources, such as remote sensing data or large text files, will require cooperative support. The resulting interdependence will not easily coexist with institutional pride.

Finally, we need to recognize that though technological developments will force changes, we can shape the way technology is used. People, not machines, create institutions. We, not the machines, will invent the electronic university.

\section{Notes}

1. Many of the papers presented at the Purple Sage Conference were reprinted in the November 1986 of College $\mathcal{E}$ Research Libraries. The Wingspread Conference is reported in Campus of the Future: Conference on Information Resources, Wingspread Conference Center, June 22-24, 1986 
(Dublin, Ohio: OCLC, 1987).

2. Patricia Battin, "The Library: Center of the Restructured University," College \& Research Libraries 45:176 (May 1984).

3. Patricia Battin, "Research Libraries in the Network Environment: The Case for Cooperation," Journal of Academic Librarianship 6:69 (May 1980).

4. Hugh Kenner, "Libraries and Glowlamps: A Strategy of Reassurance," Scholarly Publishing 18:17 (Oct. 1986). p.166.

5. Wilfred Lancaster, Toward Paperless Information Systems (New York: Academic Pr., 1978),

6. Richard M. Cyert, "Why I Believe There Is a Revolution Under Way in Higher Education," in Campus of the Future, p.13-21. 1985).

7. Derek Bok, “Looking into Education's High-Tech Future," EDUCOM Bulletin 20:17 (Fall

8. Gregory A. Jackson, “Technology and Pedagogy: Making the Right Match Is Vital,” Change 18:52-57 (May/June 1986).

9. Kenneth A. Bruffee, “The Art of Collaborative Learning: Making the Most of Knowledgeable Peers," Change 19:44 (Mar./Apr. 1987).

10. Maurice Glicksman, "Computer Technology and the Three Cs of Higher Education," in Campus of the Future, p.28-29.

11. Judith Axler Turner, "Software for Teaching Given Little Credit in Tenure Reviews," Chronicle of Higher Education 33:1,20 (Mar. 18, 1987).

12. Richard L. Van Hom, "How Significant Is Computing for Higher Education?" EDUCOM Bulletin 20:8 (Spring 1985).

13. "Grolier Licenses On-Site-Storage of Encyclopedia," Information Today 4:26 (Feb. 1987).

14. Miriam A. Drake, "Library 2000-Georgia Tech: A Glimpse of Information Delivery Now and in the Year 2000," Online 11:45-48 (Nov. 1987).

15. John Sack, "Converging Technologies: The Library"(A panel discussion at the 1986 proceedings of the Snowmass Seminar on academic computing).

16. Vannevar Bush, "As We May Think," Atlantic Monthly 176:106-7 (July 1945).

17. Quoted in William D. Garvey, Communication: The Essence of Science, (New York: Pergamon Pr., 1979), p.ix.

18. Kenner, "Libraries and Glowlamps," p.17-18.

19. Ibid., p.18.

20. See for example, John W. Senders, "I Have Seen the Future, and It Doesn't Work: The Electronic Journal Experiment," in Scholarly Publishing in an Era of Change: Proceedings of the Second Annual Meeting Society for Scholarly Publishing, Minneapolis, Minnesota June 2-4, 1980, p.8-9.

21. See: Priscilla Oakeshott, "The 'BLEND' Experiment in Electronic Publishing," Scholarly Publishing 17:28-29 (Oct. 1985), or D.J. Pullinger, "Chit-Chat to Electronic Journals: Computer Conferencing Supports Scientific Communication," IEEE Transactions on Professional Communication PC 29:23-29 (Mar. 1986).

22. Donald Case, "The Personal Computer: Missing Link to the Electronic Journal?" Journal of the American Society for Information Science 36:311 (Sept. 1985).

23. Herbert C. Morton and Anne Jamieson Price, "The ACLS Survey of Scholars: Views on Publishing, Computers, Libraries," Scholarly Communication no.5:7 (Summer 1986).

24. Oakeshott, "The 'BLEND' Experiment," p.34.

25. Bryan Pfaffenberger, "Research Networks, Scientific Communication, and the Personal Computer," IEEE Transactions on Professional Communications PC 29:32 (Mar. 1986).

26. Michael Spitzer, "Writing Style in Computer Conferences,"IEEE Transactions on Professional Communications PC 29:19-22 (Mar. 1986).

27. Kenner, "Libraries and Glowlamps," p.21.

28. Alan Singleton, "The Electronic Journal and Its Relatives," Scholarly Publishing 13:5 (Oct. 1981).

29. Douglas E. Van Houweling, "The Information Technology Environment of Higher Education," in Campus of the Future, p.70.

30. Duncan Neuhauser and Kathleen Smith, "Editorial: Accessible Microcomputer Programs as Scholarly Publications," Medical Care 25:581 (July 1987).

31. Morton and Price, "The ACLS Survey of Scholars," p.6.

32. Gordon B. Neavill, "Electronic Publishing, Libraries, and the Survival of Information," Library Resources and Technical Services 28:77 (Jan./Mar. 1984).

33. Timothy C. Weiskel, "Libraries as Life-Systems: Information, Entropy, and Coevolution on Campus," College \& Research Libraries 47:546-49 (Nov. 1986).

34. David Hessler and Jerry Miller, "Print: A New Medium for Distributing Machine-Readable Information," Library Hi Tech News 28:1, 7-10 (June 1986). 
35. D.I. Raitt, "Electronic Publishing-A View from the Library," Electronic Publishing Review 5:209 (Sept. 1985).

36. Van Houweling, "The Information Technology Environment in Higher Education," p.100.

37. Patricia Battin, "The Electronic Library-A Vision of the Future," EDUCOM Bulletin 19:13 (Summer 1984).

38. See for example: Battin, "The Electronic Library"; Van Horn, "How Significant is Computing for Higher Education"; Pat Molholt, "On Converging Paths: The Computing Center and the Library," Journal of Academic Librarianship 11:284-88 (Nov. 1985); C. Lee Jones, "Academic Libraries and Computing: A Time of Change," EDUCOM Bulletin 20:9-12 (Spring 1985); Raymond K. Neff, "Merging Libraries and Computer Centers: Manifest Destiny or Manifestly Deranged?" EDUCOM Bulletin 20:8-12, 16 (Winter 1985), or Richard M. Dougherty, "Libraries and Computer Centers: A Blueprint for Collaboration," College \& Research Libraries 48:289-96 (July 1987).

39. Weiskel, "Libraries as Life-Systems," p.562.

40. Barbara B. Moran, Thomas T. Suprenant, and Merrily E. Taylor, "The Electronic Campus: Impact of the Scholar's Workstation Project on the Libraries at Brown," College \& Research Libraries 48:10-11 (Jan. 1987).

41. John R. Sack, "Open Systems for Open Minds: Building the Library without Walls," College $\mathcal{E}$ Research Libraries, 47:544 (Nov. 1986).

42. Ibid., p.536.

43. Richard W. McCoy, "The Electronic Scholar: Essential Tasks for the Scholarly Community," Library Journal 110:41 (Oct. 1, 1985).

44. T.R. Featheringham, "Paperless Publishing and Potential Institutional Change," Scholarly Publishing 13:27 (Oct. 1981).

45. Evelyn Daniel, "An Examination of Faculty and Administrative Knowledge Workers and Their Major Information Support Units,"in Campus of the Future, p.52.

46. See Charles R. Martell, Jr., The Client-Centered Academic Library: An Organizational Model (Westport, Conn.: Greenwood Pr., 1983), especially chapter 3, "Restructuring the Academic Research Library," p.66-89.

47. Diane J. Cimbala, "The Scholarly Information Center: An Organizational Model," College \& Research Libraries 48:393-98 (Sept. 1987).

48. Nancy C. Kranich, "Find the Right Criteria, Then Decide about Fees," Collection Building 8:21 (1986).

49. Battin, "The Electronic Library," p.17.

50. Michael D. Cooper, "Charging Users for Library Service," Information Processing \& Management 14:422 (1978). 